\title{
Política Pública de Direito à Memória: apontamentos sobre a trajetória do Programa Pontos de Memória'
}

\section{Politique publique sur le droit à la mémoire: notes sur la trajectoire du Programme Pontos de Memória}

\author{
Marcele Regina Nogueira Pereira ${ }^{2}$ \\ DOI 10.265 I2/museologia.v9i I7.297।4
}

\begin{abstract}
Resumo
Este artigo apresenta aspectos relacionados à trajetória do Programa Pontos de Memória, uma Política Pública de Direito à Memória, idealizada pela Política Nacional de Museus (PNM) que integraram as Políticas Públicas Culturais incentivadas e implementadas entre os anos de 2003 a 2016 no Brasil. Reconhecendo o contexto político favorável ao desenvolvimento de processos museais que visavam ampliar a ideia de museu e contexto de atuação participativa e social, o texto apresenta as fases de formulação da iniciativa com destaque para as etapas metodológicas e os impactos para - campo da Museologia indicando avanços, limitações, necessidades conceituais e gestão Institucional do Programa.
\end{abstract}

\section{Palavras-chave}

Museu. Museologia Social. Política Pública. Memória.

\begin{abstract}
Résumé
Cet article présente les aspects liés à la trajectoire du programme Pontos de Memória, une politique publique sur le droit à la mémoire, idéalisée par la Politique National des Musées (PNM) qui a intégré les politiques publiques culturelles encouragées et mises en œuvre entre 2003 et 2016 au Brésil. Reconnaissant le contexte politique favorable au développement de processus muséaux qui visaient à élargir l'idée d'un musée et le contexte de l'action participative et sociale, le texte présente les phases de formulation de l'initiative en mettant l'accent sur les étapes méthodologiques et les impacts sur le domaine de la Muséologie indiquant des avancées, limites, besoins conceptuels et gestion institutionnelle du programme.
\end{abstract}

\section{Mots-clés}

Musée. Muséologie sociale. Politique publique. Mémoire.

Os museus não são apêndices do campo patrimonial; eles constituem práticas sociais específicas, com trajetórias próprias, com mitos fundadores peculiares. Sem dúvida, é possível pensar que estão inseridos no campo patrimonial, mas, ainda assim, é forçoso reconhecer que têm contribuído frequentemente, de dentro para fora e de fora para dentro, para forçar as portas e dilatar o domínio patrimonial. Ao contribuir para a constituição e a dilatação do domínio patrimonial, o campo museal se vê igualmente forçado a dilatar e reorganizar os seus próprios limites, especialmente a partir das suas práticas de mediação (PNM, 2007: 19).

\footnotetext{
I Texto adaptado da Tese de Doutoramento defendida em 2018 na Universidade Lusófona de Humanida-
} des e Tecnologias - ULHT, Lisboa.

2 Professora Adjunta de Museologia da Universidade Federal de Rondônia.

Contato: marcelle.pereira@unir.br 


\section{Primavera Museal: Política Nacional de Museus (PNM)}

Um aspecto importante da Política Nacional de Museus ${ }^{3}$ que interessa a este estudo é a iniciativa de, por meio de uma política nacional, criar mecanismos para que se reconheça e registre a garantia dos direitos de participação das comunidades nas etapas de registro e definição do que é patrimônio, especialmente aquele que se quer musealizar. Nesse caso a vinculação com as iniciativas posteriormente experimentadas estão amplamente articuladas com este princípio. As bases para o desenvolvimento do Programa Pontos de Memória estão claramente postas e a intenção de movimentar o cenário participativo e comunitário de salvaguarda e difusão do patrimônio museológico deve ser garantido aos grupos, movimentos sociais e comunidades.

A ampliação do conceito de museu e o reconhecimento de que podem existir museus de vários tipos, inclui o que seria chamado, posteriormente, de processos museais. A conformação da ideia de que os museus são processos e como tal estão em constante transformação, permite que a PNM reconheça e valorize as experiências que ainda não se configuram como museus, mas que têm força para se transformarem ou mesmo aquelas que não têm pretensão de se tornarem museus, mas que atuam com as bases conceituais da PNM, especialmente a partir das ideias veiculadas pela Museologia Social que segundo Moutinho (1993:07) "traduz uma parte considerável do esforço de adequação das estruturas museológicas aos condicionalismos da sociedade contemporânea".Acrescentamos as dimensões políticas, poéticas e pedagógicas que pautam os projetos de valorização da memória, da identidade, da garantia por direitos e a valorização da dignidade humana, discutidos pela Política Nacional de Museus. A PNM não descuidou do aspecto relacionado à sustentabilidade do patrimônio cultural submetido aos processos de musealização. Esta percepção da importância do fomento para as práticas de salvaguarda e conservação atribuía à política ainda mais respaldo junto aos setores museais, tendo em vista a lacuna de investimentos alocados para o financiamento de programas, projetos e ações desta natureza.

O diferencial da Política de Museus reside também na ênfase dada, a exemplo das políticas culturais do governo federal, à valorização, respeito e estímulo à preservação das práticas culturais; nesse caso as relacionadas à memória dos povos e comunidades tradicionais: os povos indígenas, quilombolas, ribeirinhos, em conformidade com as suas especificidades. A partir do incentivo ao trabalho dedicado das memórias destes grupos, vemos acontecer no país um aumento considerável de museus comunitários dedicados a fortalecê-los, atrelados às iniciativas de apoio governamental desenvolvidas por outras instâncias ministeriais de governo. (MORAES, 2009).

A partir dos interesses expressados pelo Governo Federal de garantir participação social nas ações empreendidas, seus Ministérios buscaram mudanças setoriais e, no Ministério da Cultura (MinC), por meio do Departamento de Museus do Instituto do Patrimônio Histórico e Artístico Nacional (Demu/ Iphan), inicia-se uma jornada de aprofundamento nas relações estabelecidas junto aos movimentos sociais. Este aspecto interessa em nossa análise, por expressar elementos importantes para a compreensão do Programa Pontos de Memória.

3 A Política Nacional de Museus (PNM) foi desenvolvida a partir de ampla participação e mobilização social junto aos profissionais de Museus e implementada pelo Ministério da Cultura em 2003. Os documentos básicos estão presentes no caderno da Política Nacional de Museus - Memória e Cidadania. O documento é composto por um objetivo geral, sete princípios orientadores e sete eixos programáticos. Cada eixo possui, ainda, entre quatro e oito subitens. 
Segundo Moraes, o grupo que esteve à frente do Demu possuía influência significativa em âmbito político na gestão do governo Lula (2003 - 20I I) e conseguiu ampliar a capilaridade e alcance das políticas públicas do campo museal: "A eleição de Lula permitiu uma aliança em que estes militantes puderam ocupar lugar central na burocracia pública federal. Este grupo era a base do DEMU” (MORAES, 2009:6I).

A Política Nacional de Museus contribuiu com a ampliação da ideia de museu que tem como base e como foco de suas ações as pessoas e os processos que valorizam as questões sociais. Em franco alinhamento com os pressupostos da Museologia Social, que segundo Santos (2014: 104) está amplamente relacionada "... a musealização de temas e problemas que estão latentes na sociedade" tais problemas para a autora "nos instiga a desenvolver novas metodologias de aplicação das ações museológicas, buscando..., soluções para problemas que não aprendemos a enfrentar e solucionar somente com os conhecimentos adquiridos na academia." Dessa forma, o Programa Pontos de Memória encontra na Museologia Social espaços que investem esforços em um discurso que potencializa a natureza social dos museus e do patrimônio museológico, rumo a uma consolidação ideológica atrelada às concepções da Política Cultural do governo que visou à participação popular na formulação de uma política pública com forte inspiração social.

\title{
Política Pública de Direito à Memória: os Pontos antes dos Pontos
}

A partir da constituição da Política Nacional de Museus, e mesmo antes de forma mais tímida, a equipe do Instituto do Patrimônio Histórico e Artístico Nacional (Demu/lphan), buscou consolidar apoio a novas experiências de museus e memória, relacionadas a comunidades e a movimentos sociais, com o intuito de acompanhar e fortalecer tais iniciativas que se organizavam. Este é o caso, por exemplo, da experiência do Museu da Maré, com um trabalho iniciado em 1997, a partir da criação do Centro de Estudos e Ações Solidárias da Maré - CEASM, com ações dedicadas à memória local,fortaleceram práticas inovadoras em direção à valorização da Memória da Maré e em consequência do Museu.

\begin{abstract}
$\mathrm{Na}$ época o CEASM, a partir de uma parceria com o Museu da Vida, estava desenvolvendo o Curso de Formação de Monitores de Museus e numa mesa da qual participaram a diretora do CEASM Cláudia Rose Ribeiro e o Prof. Mário Chagas é que se deu o encontro que abriria a possibilidade de constituição de um Museu que agregasse todas essas iniciativas de memória e contasse por meio de textos, documentos e objetos a história das comunidades da Maré ${ }^{4}$.
\end{abstract}

A partir das ações de memória já realizadas na Maré e a constatação da qualidade dos debates acerca da memória local que promoviam, ficou clara para a equipe do Demu a vocação para museu que se apresentava e, por meio de uma rede de diálogo e de parceria foram somadas as forças. O Demu atuou no sentido de incentivar a proposta, contribuindo com um discurso de potência que daria suporte a fim de consolidar a iniciativa dos que se dedicaram para a sua realização. Inegavelmente, desde então, o trabalho desempenhado pela equipe do Museu da Maré faz dele um marco para a história da Museologia Social no Brasil, servindo de fonte de inspiração para as gerações futuras de museus. Segundo a Folha de São Paulo:

$4 \mathrm{http}: / / \mathrm{w} w \mathrm{w}$.museudamare.org.br/joomla/index.phpoption=com_content\&view=article\&id=48\&ltem id $=54$. 
Rua Guilherme Maxwell, 26, atrás do SESI. Essa é a localização do mais novo museu do Brasil. Não é um endereço qualquer. Fica no meio do maior complexo de favelas do Rio, a Maré, e segundo o Ministro da Cultura, será o primeiro museu do país a funcionar dentro de uma favela ${ }^{5}$.

Em 2006, a partir da inauguração do Museu da Maré, pelo Ministro da Cultura Gilberto Gil, o campo museal é agitado. A presença e participação dos integrantes do Demu/lphan agregam valor político e institucional ao Museu e fazem dele um abre alas para o que poderia vir a ser, em termos de inovação, a atuação da Política Nacional de Museus, especialmente no que se refere à Museologia Social em nível nacional. Foi possível compreender, com o surgimento do Museu, que eram viáveis outras experiências museais surgirem a partir de processos colaborativos entre o poder público e os movimentos sociais voltados para o estímulo e valorização das trajetórias e cotidianos de cultura e memória de grupos minoritários e excluídos socialmente, por meio do destaque dado as luta e resistências em narrativas colaborativas e representativas a partir de novos lugares de fala.

A seriedade e continuidade com que o trabalho de memória do CEASM foi realizado durante os anos anteriores ao Museu, permitiram bases mais concretas para a construção da narrativa do Museu da Maré, pautada por um discurso socialmente referendado, crítico e politizado que desafia e propõe a ampliação do entendimento sobre a comunidade e sua história. $O$ Museu da Maré pode ser percorrido por 12 tempos que atrelados à percepção de seus moradores, ilustram as facetas de uma vida de sonhos, esperanças e medos.

O Museu da Maré ao contrário do que reforçou a mídia, não é importante apenas por ser um museu em uma favela, o seu grande diferencial é ser um espaço que valoriza a memória local por meio dos testemunhos e participação dos seus moradores. Garantindo assim representatividade e interlocução com os interesses de uma comunidade que tem a oportunidade de entrar em contato com suas vivências e lembranças.

Este espaço se constitui como uma das experiências museais mais emblemáticas para o campo dos museus em especial para o fortalecimento da Política Nacional de Museus. Com a oferta de oficinas, reuniões de trabalho, estudo e visitas a outras instituições, além de intercâmbios o Demu projetava os primeiros passos que seriam seguidos novamente, de forma mais detalhada no seu Programa Pontos de Memória, desenhado por inspiração do Ponto de Cultura Museu da Maré6.

Além do Museu da Maré, o Museu de Favela ${ }^{7}$ - Muf, pode ser considerado outra experiência museal que foi acompanhada de perto pelo Departamento de Museus do Iphan em sua jornada rumo à abertura para o público. Inaugurado em 2008, recebeu em sua cerimônia de abertura o lançamento do Programa Pontos de Memória como reconhecimento do trabalho desenvolvido e fonte de inspiração para as demais práticas que seriam estimuladas ao longo do desenvolvimento do Programa. Com estrutura bastante diferenciada do Museu da Maré, no entanto, com a mesma vocação e responsabilidade, o Muf dá início a sua trajetória por meio da atuação de um grupo de moradores interessados em experimentar a memória como fonte e recursos para a garantia de melhorias

5 Publicado em Revista Musas, IBRAM, 2007. Museu da Favela da Maré: memórias e narrativas a favor da dignidade social. file:///E:/Museu_Favela_da_Mare_Musas.pdf

6 O Museu da Maré é contemplado pelo edital Pontos de Cultura do Ministério da Cultura, desenvolvido no âmbito do Programa Cultura Viva de 2005.

7 Mais informações sobre a atuação do Museu de Favela, acessar: www.museudefavela.org 
das condições de vida, segurança, educação e cultura.

Outra experiência importante para esta conjuntura que antecede ao Programa Pontos de Memória foi a atuação da Rede de Museus, Memória e Movimentos Sociais ${ }^{8}$ nascida em 2007, contribuiu para a construção de bases mais sólidas para o processo que veríamos ver crescer anos mais tarde. Já conectada com os pressupostos de uma atuação em rede articulou em torno do tema Museus e Museologia Social, agentes de memória e militantes sociais que mobilizavam o campo dos museus já com perspectivas dedicadas a uma memória insurgente.

O Museu Vivo de São Bento em Duque de Caxias na cidade do Rio de Janeiro, o Ecomuseu da Amazônia em Belém do Pará e outras iniciativas espalhadas pelo país, agregam conhecimentos para as práticas de sistematização e apoio que serão empreendidas pelo poder público, nesse caso, o Iphan, para o desenvolvimento da proposta do Programa Pontos de Memória. No entanto, para que mais iniciativas pudessem ser mapeadas, apoiadas e fortalecidas era necessário criar condições políticas e econômicas. Para tanto, com vistas a ampliar a capacidade de atuação da equipe, algumas estratégias de parceria foram pensadas, a partir do investimento em articulações interministeriais e com organismos de cooperação internacional.

\section{As parcerias: o Pronasci e o Prodoc}

O Departamento de Museus e Centros Culturais do Instituto do Patrimônio Histórico e Artístico Nacional possuía interesse em seguir construindo parcerias interministeriais e, com isso, ampliar significativamente a capacidade técnica, operacional e orçamentária de sua gestão junto ao campo dos museus. Com a perspectiva de estarem atreladas as demais políticas públicas desenvolvidas pelo Governo Federal, exercitando uma prática de fortalecimento entre ações governamentais que possuíam objetivos comuns, por meio de atuações conjuntas e colaborativas o Demu/lphan, identificou no Programa Nacional de Segurança com Cidadania - Pronasci, iniciativa desenvolvida pelo Ministério da Justiça uma possibilidade de atuar junto aos desafios comuns de ambos os programas.

Desenvolvido pelo Ministério da Justiça no âmbito do Governo Lula, o Programa Nacional de Segurança Pública com Cidadania - Pronasci nasce de uma tentativa de enfrentamento à criminalidade no país, em articulação com políticas de segurança atreladas a ações sociais. Com vistas a eliminar as causas que levam à violência, busca atrelar ordenamento social e segurança pública. $A$ segurança só pode ser garantida, segundo os princípios do Pronasci, se alternativas para o equilíbrio social também forem experimentadas. A partir de eixos distintos e complementares, como: valorização profissional que atua com a segurança pública; reestruturação do sistema penitenciário; combate à corrupção policial e o envolvimento da comunidade na prevenção da violência, o Programa pretende atingir além dos profissionais, jovens de 15 a 29 anos que estejam sob risco de praticar crimes, ou que estejam em conflito com a lei. Esses jovens, especialmente os reservistas, são passíveis de serem aliciados pelo crime organizado exatamente por terem conhecimentos de armamentos e manejo em função do aprendizado no serviço militar. Foram selecionadas 12 cidades brasileiras localizadas em regiões metropolitanas e, segundo visão do Pronasci, con- 
Política Pública de Direito à Memória:

apontamentos sobre a trajetória do Programa Pontos de Memória

sideradas mais violentas, identificadas por pesquisa elaborada pelos ministérios da Justiça e da Saúde, e indicadas para receberem as ações do Pronasci: Belém, Belo Horizonte, Brasília (Entorno), Curitiba, Maceió, Porto Alegre, Recife, Rio de Janeiro, Salvador, São Paulo, Vitória e Fortaleza. (Ministério da Justiça, 2007).

A indução das cidades, pelo Pronasci ao Programa Pontos de Memória, foi algo que alterou consideravelmente os rumos da iniciativa em seus primeiros momentos. A esta altura já era claro que o Demu possuía articulações em várias regiões do país e precisava de estrutura para continuar apoiando as experiências em formação com o objetivo de contribuir para o seu desenvolvimento. No entanto, com a exigência do Pronasci a partir das cidades alvo de suas ações e, pensando nos recursos financeiros ${ }^{9}$ que seriam alocados no Programa, a equipe de gestão optou por adotar as indicações feitas e assumiu o desafio de iniciar novos processos levando em consideração todas as dificuldades inerentes. Tal decisão significou alguns desgastes para a equipe, pois a expectativa era de que os Pontos de Memória seriam em outras regiões e cidades a partir de práticas já mapeadas e com potencial para avançar. No entanto, como alternativa, o Demu e posteriormente o Instituto Brasileiro de Museus (lbram) seguiu articulando e mantendo apoio as demais práticas, criando uma rede de apoio significativo. Exemplo disso é a participação na primeira Teia da Memória de outras iniciativas e locais para além dos indicados pelo Pronasci. Tal atitude agregou e fortaleceu o entendimento acerca dos limites de execução existentes no Programa e possibilitou a ampliação da rede de apoio do Ibram.

O Projeto de Cooperação Técnica Internacional firmado entre a Organização dos Estados lbero-americanos para a educação, ciência e cultura e o Ministério da Cultura, com o título: Desenvolvimento institucional e técnico operacional para a ampliação e consolidação de projetos relacionados à memória social no Brasil, o Prodoc, como é conhecido, foi firmado em 2008 e possui estrutura baseada no formato padrão de projeto contendo apresentação, objetivos, justificativa, orçamento, metas, ações e cronograma. As ações programadas, como o próprio título indica orientam-se para atualizar e aperfeiçoar instrumentos gerenciais e técnico-operacionais destinados "à ampliação e consolidação de estruturas de apoio cognitivo e metodológico às comunidades que atuam com memória social no Brasil” (Prodoc, 2008).

Com vistas a cumprir as metas o projeto propõe atividades pautadas pela necessidade de definição conceitual e metodológica sobre memória social, com ênfase para as relações comunitárias em auxílio ao desenvolvimento da proposta do Ponto de Memória, sua gestão e manutenção. $O$ projeto elaborado inicialmente prevê a capacitação para agentes de memória e membros da comunidade; produção de material a partir dos acúmulos gerados para consulta e formação de novos processos e a sistematização da metodologia de trabalho junto aos pontos, com a geração de instrumentos que possam auxiliar as futuras formulações, planejamento, avaliação e apoio aos Pontos de Memória.

Este documento é a base de toda a construção do Programa Pontos de Memória, norteador dos objetivos a serem alcançados, ao longo de sua vigência de 2008 a 2015. O Programa produziu avanços para o campo dos museus e da memória, especialmente no que se refere ao campo das políticas públicas em museus no Brasil, com ênfase para a participação e protagonismo de grupos

9 Importa destacar que não levaremos em consideração, nas análises aqui propostas, os valores orçamentários que foram utilizados pelo programa para o seu desenvolvimento. Consideramos que este esforço ainda precisa ser feito e certamente contribuirá com a ampliação do entendimento acerca desta prática em âmbito governamental em maior profundidade. 
e movimentos sociais. $O$ projeto produz referencial importante para traçar a trajetória do Programa e sua constituição, avanços e desafios. A partir deste instrumento, conectado com os pressupostos e desafios da PNM, com base nos fundamentos da Museologia Social e experimentados sobre forte inspiração dos Museus da Maré e do Museu de Favela, I 2 novos processos museais são criados em todo o país.

Com o intuito de executar as ideias postas nos princípios da PNM e com a missão de continuar estimulando novos processos museais com base comunitária a equipe Demu/lphan, disponibilizou apoio técnico, por meio de oficinas e orientações a grupos e comunidades que possuíssem interesse em trabalhar suas memórias por meio de ações desenvolvidas nas localidades. A ideia era contribuir com o fortalecimento de tais práticas a partir de uma discussão acerca dos temas relacionados aos museus, à memória e ao patrimônio cultural, além das técnicas e procedimentos relacionados a modelos de criação e gestão de museus. Com vistas a oferecer as condições necessárias para o incremento e fortalecimento das práticas relacionadas à criação de museus em comunidades que atuam com a identidade cultural e territorial.

Depois de firmadas as parcerias ampliar a diversidade e a capilaridade museal e garantir a forte inserção dos museus nas comunidades locais, foram desafios previstos pelo Demu/lphan e incluídos como metas e objetivos no Prodoc.

\section{Os Territórios indicados}

As localidades escolhidas possuem um perfil que as une, segundo as pesquisas indicadas pelo Ministério da Saúde e as informações da própria polícia as caracterizam como sendo violentas e com alto índice de homicídios e crimes hediondos. Possui elementos que agregam possibilidades de enfrentamento acerca da segurança pública para públicos específicos, como os jovens e as mulheres. Assim, diante das exigências estabelecidas a partir das cidades mapeadas e indicadas, era necessário que o Programa Pontos de Memória pudesse percorrer o país, com a tentativa de já identificar as experiências e convidá-la para a primeira Teia da Memória em Salvador realizada em 2010.

Em análise realizada pelo consultor Wélcio Toledo foi traçada a trajetória e a situação de cada comunidade contatada pela equipe do Programa, identificando em que situação cada uma delas estava quando a proposta chegou. Importante ressaltar que para algumas comunidades, o trabalho com a memória já era uma realidade e para outras a proposta soou como uma grande novidade. No entanto, mesmo sendo novidade, as lideranças reunidas para as reuniões com o lbram mostraram-se interessadas em fazer parte do projeto, especialmente por compreenderem como ela poderia contribuir para a consolidação do trabalho social que já estava em curso nas comunidades por movimentos diversificados.

As comunidades visitadas na primeira etapa do Programa a partir das reuniões realizadas e a identificação das experiências de memória, como proposta-piloto em 12 comunidades brasileiras, foram: Beiru (Salvador, BA), Brasilândia (São Paulo, SP), Coque (Recife, PE), Estrutural (Brasília, DF), Grande Bom Jardim (Fortaleza, CE), Jacintinho (Maceió,AL), Lomba do Pinheiro (Porto Alegre, RS), Cantagalo Pavão Pavãozinho (Rio de Janeiro, RJ), Terra Firme (Belém, PA), São Pedro (Vitória, ES), Sítio Cercado (Curitiba, PR) e comunidade do Taquaril (Belo Horizonte, MG).As reuniões foram agendadas a partir do diálogo estabe- 
lecido entre a equipe do lbram e a rede de contatos nos Estados e nas cidades indicadas, além do esforço pessoal dos consultores contratados. A partir desta aproximação inicial, eram identificados lideranças e projetos que receberiam a equipe para conhecer a proposta. Todas as primeiras visitas de aproximação e sensibilização foram realizadas em 2009, algumas localidades chegaram a receber de duas a quatro visitas, definidas a partir do amadurecimento das propostas já desenvolvidas, da articulação e demandas locais. Importante destacar que tal iniciativa acumulou diversas práticas museais que precisam ser conhecidas ou até mais bem sistematizadas.

\section{A Metodologia do Programa}

Para o cumprimento das fases previstas em Prodoc e seus objetivos, a etapa inicial relacionada ao objetivo I que orienta a contratação dos primeiros consultores e produtos, dá início ao trabalho de fortalecimento e desenvolvimento das práticas nas localidades. A metodologia do Programa Pontos de Memória foi sendo elaborada na medida em que a equipe avançava em direção às comunidades. As reuniões realizadas, as visitas técnicas a todas as localidades escolhidas e os diálogos de reconhecimento do território e de suas questões foram contribuindo para dar contorno ao método que seria utilizado no Programa.

Em princípio a falta de método permitiu que o grupo avançasse, pois o trabalho de reconhecimento dos potenciais de cada lugar, os grupos e coletivos que já desempenhavam papel de agentes de memória com iniciativa política e social, foram tornando-se ao longo do processo, grandes descobertas e aprendizados. No entanto, era preciso seguir alguma diretriz que pudesse ajudar no cumprimento das metas e objetivos estabelecidos. Assim, a partir das considerações realizadas pelos consultores como resultado das visitas técnicas, algumas etapas foram consolidadas ${ }^{10}$.

As propostas apresentadas pela consultoria foram destacadas a partir das visitas realizadas as localidades, o que acarretaram forte impacto sobre os desdobramentos que seriam necessários para a execução da proposta a partir daí. A etapa da sensibilização pode ser considerada a primeira etapa do Programa, pois foi possível, por meio dela, conhecer as práticas e estabelecer os primeiros contatos para a apresentação da proposta.

A I Teia da Memória realizada na cidade de Salvador, Bahia, em dezembro de 2009, coroou toda a primeira fase do Programa. Com a participação de representantes de cada Ponto de Memória uma rede se consolidava. Esta ação contribuiu para ajustar e ampliar a compreensão dos participantes sobre o Programa e dar início a realização. Em ação recorde, durante o ano de 2009, todas as localidades foram identificadas, os contatos foram realizados e as mobilizações foram feitas.

O espírito do trabalho coletivo (co) responsabilizado e ciente do papel de destaque e protagonismo dos grupos comunitários pode ser expresso a

10 Consultor:TOLEDO,Wélcio, 2009. Produto 2. Documento preliminar sobre metodologia para implantação dos Pontos de Memória (outubro de 2009). I) A sondagem e contatos com as comunidades de "risco social" indicadas pelo Pronasci (no período de 3 meses, de setembro a novembro de 2009); 2) Intercâmbio entre as comunidades para que elas conheçam o Programa Pontos de Memória e troquem experiências (em dezembro de 2009); 3) Diagnóstico das potencialidades presentes nas comunidades para a implantação de Pontos de Memória (de janeiro a março de 2010); 4) Oficinas de capacitação para os agentes de memória da comunidade, com 10 temas diferenciados, atendendo turmas de 15 pessoas (março a maio de 20।0); 5) Elaboração do inventário patrimonial das comunidades (janeiro a unho de 2010); 6) Elaboração de um plano de trabalho para cada Ponto de Memória, como produto final das oficinas (TOLEDO, 2009). 
partir do entendimento de Chagas, quando diz que:"O poder público precisa aprender a pescar, e quem ensina é a sociedade" ". Em constante mutação, durante o processo de criação e desenvolvimento da proposta, foi possível observar as dificuldades enfrentadas pela equipe de gestão e também pelos integrantes dos Pontos e as alternativas para enfrentar os desafios.

A primeira etapa do Programa, composta por: contatos prévios, contratação de consultores, visitas técnicas, reconhecimento das ações realizadas pelas comunidades visitadas, definição das localidades e a realização da I Teia da Memória, são estratégias metodológicas que fazem parte da primeira fase do Programa, que chamaremos aqui de ${ }^{a}$ Fase: Sensibilização.

A segunda etapa do Programa possui como forte elemento metodológico o desenvolvimento dos conselhos gestores, a elaboração e execução dos Planos de Ação além da realização das oficinas e encontros com os consultores. Esta etapa teve início em 2010, logo após a realização da I Teia da Memória.

A iniciativa do Programa Pontos de Memória tem como finalidade a participação dos grupos, coletivos e movimentos sociais no desenvolvimento das práticas de memória em favor das reivindicações sociais por saúde, moradia, educação, cultura e, nesse caso, especialmente, o direito à memória. Com a consolidação das plenárias, reuniões, assembleias, seminários e outras iniciativas realizadas para a discussão e identificação dos representantes locais, foi possível avançar no planejamento das ações e fortalecer a dinâmica de representatividade, tão importante como concepção original do Programa.

O estímulo à criação das Instâncias Deliberativas pela equipe do lbram tornou-se aliado para o acompanhamento da tomada de decisão sobre os encaminhamentos relativos aos assuntos dos Pontos. Com o grupo formalizado, diminuiriam as chances de uma atuação mais vulnerável à vontade e deliberações de um só movimento que poderia não representar um conjunto maior de pessoas. No entanto, esta estratégia não tornava o processo livre dos conflitos internos por poder e por protagonismo seja político ou pessoal. A esse respeito o Ponto de Memória Mangue do Coque, Ponto de Memória do Beiru e o Ponto de Memória do Taquaril tem exemplos importantes a serem considerados nesta análise. A respeito da configuração da Instância Deliberativa do Taquaril, Leila Regina da Silva, nos diz:

...fazer parte do conselho é assumir o trabalho de fazer o projeto acontecer na nossa comunidade. "Olha, eu vou estar no conselho, mas eu tenho que fazer reuniões periodicamente, fazer as atividades que o projeto propõe, mobilizar a comunidade..." (...) Agente precisa da comunidade, de vocês, para dizer se a proposta para conduzir esse projeto na comunidade é essa mesmo que a gente está apresentando, ou seja, de ter um conselho que é composto por pessoas que fazem parte das entidades que existem em nosso bairro, das várias entidades. Não há restrição a participação de ninguém no conselho! $(\ldots)^{12}$

II Mário Chagas, Diretor do Departamento de Processos Museais do lbram na fala de encerramento da $I^{\text {a }}$ Teia da Memória. 17 de dezembro de 2009, Salvador, Bahia. In: GOUVEIA, Inês. 20II. Produto 2 - Registro do processo de concepção do Projeto Pontos de Memória desde a sua proposição no âmbito do Pronasci-MJ

12 Fragmento da fala de Leila Regina da Silva, integrante do Ponto de Memória do Taquaril em I3 de novembro de 2010. Belo Horizonte, Minas Gerais. In: GOUVEIA, 20I I. Produto 4. Relatório das estratégias adotadas para a formação das instâncias deliberativas dos Pontos de Memória, como parte do desenvolvimento do modelo de gestão (setembro de 20I0). Expresso no Termo de Referência (TOR), sob coordenação do Instituto Brasileiro de Museus - Ibram em parceria com o Ministério da Justiça, no âmbito do Programa Nacional de Segurança com Cidadania - Pronasci e a Organização dos Estados lbero-americanos - OEl. 
Política Pública de Direito à Memória:

apontamentos sobre a trajetória do Programa Pontos de Memória

Assim, foi necessário contribuir para que as localidades elegessem seus representantes a fim de que as iniciativas e tomadas de decisão pudessem respaldar a opinião e participação de mais moradores e integrantes da comunidade. Este aspecto deve ser ressaltado como um dos grandes avanços do Programa ao identificar a necessidade de promover condições para que as lideranças possam se articular e promover a institucionalização da experiência participativa, identificando os nomes e assinaturas daqueles que integram a gestão do Ponto de Memória. Esta etapa pode ser descrita a partir da dinâmica de cada localidade, pois as experiências podem ser observadas por aspectos diferentes que se relacionam diretamente com a dinâmica do ponto, seu contexto, conflitos ${ }^{13}$.

$\mathrm{Na}$ medida em que os Pontos de Memória organizavam suas ações, cada um a seu modo, as instâncias deliberativas ou conselhos gestores, foram tornando-se cada vez mais autônomos para desenvolver seus processos o que significava, inclusive, angariar apoio financeiro para a realização das atividades a partir das deliberações dos gestores.

Atrelado ao desenvolvimento das oficinas de formação, parte integrante da estratégia metodológica de fortalecimento dos Pontos pelo lbram, foi pensado um Plano de Ação - PA que deveria ser realizado por iniciativa, a partir de um modelo comum de preenchimento, com formato padrão para a inclusão de cronogramas, projeto e intenções de realização dos pontos. Este instrumento foi pensado para que o recurso financeiro pudesse chegar diretamente a cada iniciativa, já que não era possível por meio da execução via Prodoc outra forma de repassar recursos financeiros para os pontos de forma direta. $\bigcirc$ modelo de cooperação com a Organização dos Estados Ibero-americanos - OEl, tem caráter extremamente focado na formação e colaboração para ferramentas metodológicas de gestão e não no desenvolvimento de práticas relacionadas ao fomento e financiamento das experiências.

Dessa forma, foi preciso pensar em uma estratégia que pudesse solucionar a falta de recursos nos Pontos dentro dos padrões legais exigidos pela Cooperação Técnica. Surge, neste momento, à figura do Consultor Local contratado para estabelecer vínculo e relacionamento direto com os gestores do Ponto, uma das exigências do Termo de Referência - TOR, destes consultores seria residir ou ter vínculos próximos com a comunidade atendida, assim seus produtos viabilizariam ações locais e o grupo estabeleceria com o consultor a melhor forma de realização das atividades propostas. Essa foi a única vez em todo o desenvolvimento do Prodoc, com exceção do Prêmio Pontos de Memória, que os Pontos receberam diretamente algum tipo de recurso para viabilizar suas ações.

A partir da atuação dos consultores locais contratados, o lbram passou a desenvolver junto aos Pontos de Memória uma estratégia de acompanhamento, por meio do trabalho dos consultores e diálogo, além destas estratégias foram realizadas oficinas de qualificação para que os integrantes pudessem receber formação. As oficinas realizadas: Museu, Memória e Cidadania, uma das primeiras ofertadas, exatamente por seu caráter introdutório e as oficinas de Inventário Participativo (IP). Além destas mais comuns nas primeiras fases do Programa, outras viriam a ser realizadas.

I3 A esse respeito consultar os produtos: TOLEDO, Wélcio Silvério de. Produto 02 ( $1^{\circ}$ contrato); VARANDA, Ana Paula. Produto 0 I (20I0); GOUVEIA, Inês Cordeiro. Produto 04 e 07 (I ${ }^{\circ}$ contrato);

SCHUABB, Sara. Produto 5 ( $3^{\circ}$ contrato). 
Além deste encontro durante as fases do Programa outras oficinas foram realizadas nos Pontos de Memória com a equipe do lbram, composta por servidores, consultores, colaboradores, além dos intercâmbios promovidos pelo Instituto e aqueles promovidos pelos próprios pontos com recursos de suas bases. No entanto é importante notar que ainda neste ponto, mesmo com os esforços empreendidos pelo lbram, muitos pontos identificam uma grande ausência de oficinas atribuindo, inclusive, a isto o atraso no desenvolvimento das experiências.

A partir das oficinas de formação e do preenchimento do PA, os pontos iniciaram o desenvolvimento de seus Inventários Participativos, parte importante da metodologia do Programa. Após o desenvolvimento dos seus Inventários, os Pontos deveriam difundir suas conquistas relacionadas ao acúmulo de informações sobre o território, suas memórias, identidades, fechando assim um ciclo de criação. Os Produtos de Difusão - PD representam as escolhas poéticas para o reconhecimento do território por meio de ações concentradas em recolher depoimentos e acervos para um banco de informações sobre a região. Por meio de iniciativas de memória, entrevistas, encontros, chás, rodas de conversas, feiras, os grupos obtêm informações a partir das histórias de cada localidade, além de todas as manifestações possíveis de serem recolhidas desde as experiências da comunidade. $\mathrm{Na}$ medida em que este trabalho se concretizava, era preciso divulgá-lo para alcançar mais moradores, mais parceiros, noticiando a experiência vivida e ampliando a capacidade de atrair mais interessados em manter viva as memórias e as histórias colaborando para o fortalecimento do Ponto e dos processos museais ali desenvolvidos.

A seguir apresentamos um gráfico que demonstra os elementos centrais para a constituição dos Pontos de Memória. Deixamos de fora a etapa inicial de sensibilização, pois levamos em consideração a já identificação da iniciativa para o início das atividades propostas. Com formato circular, cada etapa é complementar e nenhuma pode ser considerada sem a outra. Todas influenciam de forma direta o desenvolvimento do Programa e revelam o seu caráter dinâmico, integrado e cíclico:

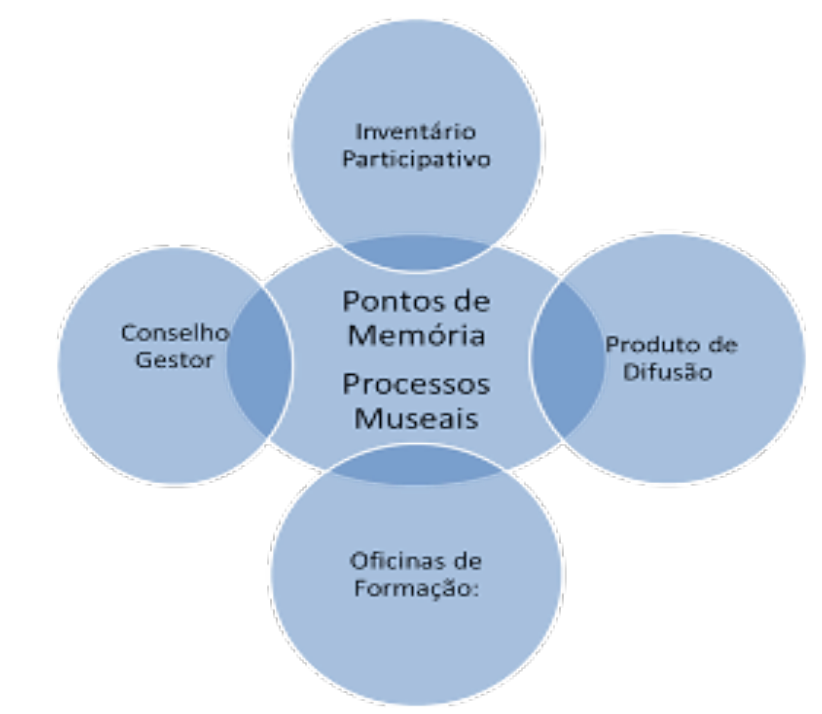

Esquema I. Estrutura Metodológica Programa Pontos de Memória. Elaboração da autora. 


\title{
As Teias da Memória
}

A primeira Teia da Memória aconteceu em dezembro de 2009 e reuniu os integrantes dos Pontos de Memória e outros representantes da Museologia Social que se fortalecia já neste período de forma mais diretamente apoiada pelo Instituto Brasileiro de Museus. Este encontro, inspirado pela realização das Teias de Cultura, no âmbito do Programa Cultura Viva, do Ministério da Cultura, trilhava seus passos por caminhos diferentes. A Teia se constituía como principal canal de articulação entre as localidades indicadas para receber a proposta do Programa Pontos de Memória, além de também receber outras experiências museais, como o Museu Magüta em Benjamin Constant no Amazonas, o Museu da Maré do Rio de Janeiro e o Ecomuseu da Amazônia em Belém do Pará, para que pudessem compartilhar as experiências e contribuir com a consolidação da iniciativa em âmbito Nacional.

Simone, professora do Centro de Atenção Integral da Criança (Caic) do Bairro Novo em Sítio Cercado, articuladora do Programa Ponto de Memória em seu discurso, por ocasião da I Teia da memória, indica que:

\begin{abstract}
A luta hoje no bairro já não é mais por paredes, por água, por esgoto. Essa estrutura mínima, para se levar uma vida digna já existe. Hoje o que está faltando é a cultura.As pessoas do bairro têm muito pouco acesso à cultura. Isso porque a prefeitura do bairro não valoriza o Sítio Cercado como merecedor desse tipo de atenção. (...) Pensam que o Sítio Cercado é uma favela. (...) Temos bolsão de pobreza, mas a maioria da população tem casa própria e carros. $\bigcirc$ que acontece, por não ter nenhuma atenção, a maioria dos jovens fica desocupada, e então buscam outras 'experiências'. Então precisamos mesmo de trabalhar com cultura. (Depoimento de Simone. In: FERNANDES, 20 I0:23)
\end{abstract}

A II Teia da Memória, dentro da programação da TEIA Brasil demostrou a aproximação necessária e inevitável com o Programa Pontos de Cultura, iniciativa também do Ministério da Cultura. Em 2010, portanto, segundo ano de desenvolvimento do Programa Pontos de Memória, em Fortaleza aconteceu a Teia Brasil Tambores Digitais, organizado pela Secretaria de Cultura e Cidadania do Ministério da Cultura, já em sua quarta edição. A III Teia da Memória realizada em 20I I, no Museu da Maré, garantiu aos Pontos conhecer uma das iniciativas mais emblemáticas de Museologia Social no Rio de Janeiro e grande fonte de entusiasmo acerca do desenvolvimento do Programa Pontos de Memória. A experiência de formação, trocas e perspectivas, caracteriza um momento de forte aglutinação e fortalecimento das iniciativas, que a cada encontro tornam-se mais comprometidas com o tema, assumindo já um discurso em favor das práticas museológicas e processos museais em comunidades que fazem a própria gestão e as escolhas que darão vida a reflexão sobre a importância da memória para as questões do território.

Consideramos a realização das Teias da Memória, momento oportuno para o fortalecimento das ações em rede e do aprofundamento das reflexões que contribuiriam para o acúmulo de experiências necessárias para o desenvolvimento da Museologia Social no Brasil. Importante destacar que estes momentos de troca, significaram também oportunidade para que as práticas pudessem estabelecer parâmetros para as solicitações ao Instituto Brasileiro de Museus, no momento, principal articulador e fomentador destas redes em surgimento. Com o propósito inicial de reunir as iniciativas para que estas pudessem compreender um cenário de franco crescimento, o lbram também se alimentava das 
questões e das solicitações a que era constantemente submetido pelas experiências. As possibilidades de articulação entre governo e sociedade civil, que levando em consideração as disputas por autonomia e ao mesmo tempo um desejo de "tutela" levam os Pontos de Memória e as demais iniciativas a reverem seus próprios propósitos.

A esse respeito, discutindo a situação vivida pelos Pontos de Cultura, ao se estabelecerem para além do Programa Cultura Viva, com o fortalecimento do Movimento e aprovação da Lei Cultura Viva, demostram o potencial que existe nas articulações populares frente aos desejos por autonomia em relação ao Estado.

\begin{abstract}
Por diversas razões, entretanto, com o avançar da execução do programa, os Pontos de Cultura vão se tornando autônomos em relação ao público que a princípio representavam. Eles mesmos vão se produzindo como a população objeto da política de governo. A percepção desta autonomização como possibilidade de disputa política alimenta a formação de instâncias como o Fórum Nacional dos Pontos de Cultura e o Conselho Nacional dos Pontos de Cultura. (PORTILHO, 20 I6:66)
\end{abstract}

Destaco essa passagem como indicativo de que a situação vivenciada pelos Pontos de Memória a partir, especialmente, da IV Teia simbolizam exatamente esse processo de produção de novas instâncias articuladoras a partir das disputas que os movimentos em rede são capazes de mobilizar. Para os Pontos de Memória e a constituição da Comissão Provisória de Gestão Compartilhada/ Participativa do Programa Pontos de Memória Cogepaco ${ }^{14}$, são processos similares e compreensíveis, o que demostra que a estratégia adotada pelo lbram de fortalecer as iniciativas em rede deu certo e foi ainda mais impulsionada pelos movimentos do Programa "primo" Pontos de Cultura.

A realização da IVTeia da Memória como parte integrante do Fórum Nacional de Museus, pode ser considera um marco para a estrutura do Programa Pontos de Memória. Com composição totalmente diferente das teias anteriores, esta assumiu um contorno extremamente político e reivindicatório, marcando também um momento de desentendimento e cisão entre as perspectivas dos Pontos de Memória trabalhados na primeira e segunda fase do Programa e os Pontos de Memória premiados por meio dos editais.

Caracterizada por inúmeros conflitos de natureza política, a IV Teia quase não debateu e discutiu aspectos conceituais ou mesmo metodológicos. $O$ foco esteve centrado na questão da representatividade e legitimidade, geradas por conta de uma falta de entendimento acerca dos princípios norteadores do Programa, seus acúmulos pretendidos em sociedade e uma disputa acerca de protagonismo diante das demandas políticas de Estado.

Ainda segundo a Rede São Paulo de Memória e Museologia Social, a IV Teia, não considerou a integração entre as iniciativas gerando profundo desgaste ao longo de todo o processo. $O$ que deveria servir para aglutinar ideias e provocar debates acerca de outras oportunidades de fortalecer as iniciativas agregando saberes e fazeres acabou por configurar um grande espetáculo de disputas entre as iniciativas sem a capacidade gerencial do Instituto que pretendia com a Teia promover a integração a acumular avanços. Holanda (20I5: 55) em seu relatório recupera o que indicou a Rede de São Paulo em carta enviada ao Ibram:

14 Comissão Provisória de Gestão Compartilhada/Participativa do Programa Pontos de Memória - Cogepaco, criada em 2012, por ocasião doV Fórum Nacional de Museus, em Petrópolis-RJ. 
Embora, nos intervalos e momentos de descontração, tenha ocorrido a aproximação e inter-relação dos representantes dos Pontos de Memória, sentimos a ausência de uma proposta estruturada para a acolhida, socialização e integração deles, sobretudo, antes dos debates/plenárias. Devido ao distanciamento geográfico, ausência de fomento para intercâmbios e desconhecimento da maioria das iniciativas presentes, em relação aos trabalhos desenvolvidos pelas próprias iniciativas do PPM, vimos refletido de forma intensa e negativa estas ausências, em diversos momentos da plenária. Concluímos que, em alguma medida, a dinâmica (ou ausência dela) comprometeu o que consideramos princípios de cooperação e potencialidades das próprias iniciativas, inclusive documentados de forma simbólica, afetiva e objetivamente política, na "carta da rede dos pontos de memória e iniciativas comunitárias em memória e museologia social."

Por meio das considerações da Rede de São Paulo, percebemos que a Carta da Rede dos Pontos de Memória e Iniciativas Comunitárias em Memória e Museologia Social ${ }^{15}$ firmada ainda em 2012 com elementos bastantes claros indicativos de avanços já considerados na época e, em perspectiva amplamente agregadora de todas as experiências que viriam a somar a estrutura nacional do programa, foi solenemente ignorada na configuração e nas propostas indicadas a partir do V Fórum de Museus.

\section{Processo de Institucionalização}

Em conformidade com a ampliação do Programa e as mudanças de gestão a partir de 2012, foi realizado na sede do Ibram em Brasília, entre os dias 4 a 6 de junho o Encontro de Articulação de Redes de Pontos de Memória e Museus Comunitários, com a participação de 32 representantes do campo da Museologia Social das cinco Regiões do País e a equipe técnica do lbram. Este poderia ter sido mais um dos encontros realizados pela equipe com as lideranças das iniciativas, se não fosse pela construção conjunta de um dos instrumentos que podem ser considerados mais significativos destas fases iniciais do Programa. Julgamos como um marco sua produção, pois o Instituto propõe aos integrantes do Programa, somadas às iniciativas de memória contempladas em editais e iniciativas parcerias, a sua organização em redes para que possam obter mais amplitude para suas ações. É importante destacar que até este momento poucas articulações em rede tinham surgido no país e as poucas que já se articulavam estavam presentes neste encontro contribuindo e muito com as discussões propostas. $O$ documento construído foi a já citada Carta da Rede dos Pontos de Memória e Iniciativas Comunitárias em Memória e Museologia Social, nome escolhido a partir de intenso debate, com o intuito de incluir as diversificadas experiências que se articulavam em torno do Programa e para além dele.

O documento elaborado por todos os participantes e finalizado pela equipe do lbram propunha uma síntese das discussões que foram tidas durante os dias de encontro com propostas voltadas para "para fomento, financiamento e sustentabilidade, qualificação, inventário participativo e articulação em rede. Em plenária, os participantes decidiram que o documento ainda deverá ser debatido em suas comunidades e estados, para ser referendado na IV Teia

I5 Carta da rede dos pontos de memória e iniciativas comunitárias em memória e museologia social, 20I2, pode ser acessada no link: museuscomunitarios.files.wordpress.com/20 I4/0 I/carta-das-redes-de-pontos-de-memc3b3ria-e-museus-comunitc3al rios.pdf ou https://www.museus.gov.br/wp-content/ uploads/2012/06/Minuta_MuseologiaSocial_PontosdeMemoria.pdf 
da Memória"16. As propostas defendidas estão baseadas em alguns princípios que merecem ser debatidos e compreendidos no âmbito desta Política Pública. Nota-se que a reunião acontece em Brasília, na sede de uma autarquia do Ministério da Cultura, com a presença de lideranças representativas de todas as regiões brasileiras para construir um documento que valorize e priorize a participação de processos museais comunitários e participativos nas ações do Ibram, garantindo a autonomia e estratégias de sustentabilidade.

Para aprofundarmos as questões relacionadas a ampliação das redes de Pontos de Memória e Museologia Social que surgem é importante considerar a pertinência deste documento e sua riqueza de possibilidades frente a consolidação e crescimento das experiências por meio das redes, que incentivadas pelo Ibram já em junho de 2012 considerava ser esse o caminho e futuro do Programa Pontos de Memória, apostando na integração e participação. Além da existência das redes nacionais ${ }^{17}$, é importante registrar a experiência Latino Americana bastante produtiva, especialmente neste contexto de influência exatamente pelo impacto de ideias e iniciativas que geram. Por exemplo a existência da União dos Museus Comunitários, da União Nacional de Museus Comunitários e Ecomuseus, da Rede de Museus Comunitários da América ${ }^{18}$.

A partir da articulação em rede, os movimentos são fortalecidos pelas trocas que são promovidas, pelos auxílios mútuos, pela difusão de ideias e projetos que fomentam as ações e especialmente se fortalecem para buscar sempre o comprometimento dos órgãos públicos com vista a manutenção, fomento e formação técnica. Desse modo as redes e a criação da Cogepaco, - compreendemos que esta instância já aparece como reivindicação na Carta da Rede dos Pontos de Memória e Iniciativas Comunitárias em Memória e Museologia Social: "9. Estimular processos de institucionalização para os Pontos de Memória e demais iniciativas comunitárias em memória e museologia social, que garantam autonomia dos processos de gestão, tais como implementação de um estatuto e constituição de personalidade jurídica (identidade legal)", mobilizam o Instituto Brasileiro de Museus a pensar formas de concretizar a institucionalização do Programa no âmbito de suas responsabilidades institucionais. Depois de debates, atrasos por parte do lbram e de inúmeras reuniões para a discussão do assunto, entre os integrantes da Cogepaco e os técnicos do lbram sistematizadas também nos produtos da consultora Ana Maltez (20l3) o lbram, por meio da portaria publicada no Diário Oficial da União a Portaria n. $315^{19}$ institucionaliza - Programa Pontos de Memória. Segundo o site da Instituição "Grande expectativa do campo da museologia social brasileira, a normativa oficializa o Programa

16 Carta da rede dos pontos de memória e iniciativas comunitárias em memória e museologia social, 2012 .

17 No Brasil, a Associação Brasileira de Ecomuseus e Museus Comunitários - Abremc também merece destaque por sua atuação e interesse em aglutinar as experiências de Ecomuseus e Museus Comunitários. No entanto o que é motivo de interesse neste trabalho é a difusão das Redes de Museologia Social, especialmente uma das primeiras experiências a Rede Cearense de Museus Comunitários criada em (20l I); em 2012 vemos surgir outras duas iniciativas uma no Rio Grande do Sul e outra no Rio Grande do Norte, respectivamente Rede dos Pontos de Memória e iniciativas comunitárias em memória e museus comunitários e outra denominada Rede dos Pontos de Memória e Museus Comunitários; a Rede de Museologia Social do Rio de Janeiro e a Rede LGBT de Museologia Social do Brasil ambas com surgimento em 2013; a Rede SP de Memória e Museologia Social fundada em 2014; a Rede Indígena de Memória Social no Brasil com atuação a partir de 2015 e por último, a Rede de Memória e Museologia Social Capixaba criada em 2017. O Norte do país também se organiza em rede e promove ações integradas especialmente as promovidas pelo Ecomuseu da Amazônia, Ponto de Memória Terra Firme, Museu Goeldi e outras experiências.

18 A Rede de Museus Comunitários da América foi formada em 2000 por representantes de bases comunitárias de diferentes países como Bolívia,Venezuela, Panamá, Costa Rica, Nicarágua, El Salvador, Guatemala y México. A esse respeito ver: http://museoscomunitarios.org/redamerica

I9 A Portaria pode ser acessada no link: http://pesquisa.in.gov.br/imprensa/jsp/visualiza/index.jsp?jornal= I \&pagina $=6 \&$ data $=1 \mid / 09 / 2017$ 
Política Pública de Direito à Memória:

apontamentos sobre a trajetória do Programa Pontos de Memória

como política pública perene no âmbito de atuação do Ibram".

Sobre a portaria, importante observar 0 artigo $6^{\circ}$ que prevê a forma-

ção do comitê consultivo do Programa Pontos de Memória e sua constituição. Nesta formação além dos integrantes do lbram, chama atenção a presença dos Pontos de Memória Pioneiros, assim denominado na portaria. Consideramos esta presença algo emblemático e bastante significativo, fruto de muita negociação dentro da estrutura do programa para que pudessem ser respeitados, não só como Pontos de Memória, mas como pioneiros, por sua especificidade e compromisso institucional anteriormente firmado.

Outro aspecto importante e que merece ser destacado é a garantia de dois representantes das redes temáticas de pontos de memória, isso significa ampliação do processo de participação e amadurecimento quanto as necessidades destas redes e destes coletivos tomarem acento em representações junto ao poder público, neste caso o Ministério da Cultura por meio do Ibram.

\section{Conclusão}

Importante ressaltar o papel prioritário dado pelo Ibram ao Programa Pontos de Memória. Como vimos, essa iniciativa é articulada com a PNM, que experimenta direta e estrategicamente ações dedicadas ao desenvolvimento de processos museais em comunidades cujo tratamento aos sujeitos que vivem de forma intencionalmente subalternizada e invisibilizada visa melhorar a qualidade de vida dos povos, ao exercitar retomada, por meio da memória, da dignidade roubada e oferecer espaços para a discussão e o debate sobre garantia dos direitos. Tal iniciativa pode ser considerada inovadora no Brasil e em outros países, pois representa o Estado, por intermédio do MinC, apoiando o desenvolvimento de práticas autônomas e autogestionadas. Isso faz com que as lideranças locais invistam em criatividade e ações de cidadania participativa, além de alterar a realidade de subjugo dos povos e das comunidades tradicionais, urbanas e de minorias, para ter chances de enfrentamento às injustiças sociais.

Assim, há inovações na gestão de uma política pública que incentiva a autogestão das práticas museais em território e as articula em rede. No entanto, sem romantismo, sabemos das dificuldades desse processo e seus limites. Infelizmente, devido às descontinuidades e fragilidades institucionais o volume de expectativas criadas e frustradas junto às comunidades é grande e isso gera também resultados contrários aos objetivos da proposta. As 12 iniciativas piloto aqui elencadas, após a descontinuidade do programa, por meio da não implementação da Portaria que o institucionaliza, tiveram os seus desdobramentos metodológicos prejudicados e, por isso, buscaram articulações com outras instituições para que suas atividades não fossem completamente encerradas, no entanto, outras foram desarticuladas com as mudanças de atuação e apoio do Ibram. Este processo também necessita ser objeto de estudos aprofundados e as consequências melhor sistematizadas.

O Ibram e sua equipe, aliados a comunidades e movimentos sociais, desenvolveram uma experiência que contribuiu com a consolidação do campo da Museologia Social no Brasil, provando que é possível investir em práticas, mesmo em âmbito governamental, que estimulem a emancipação e a participação crítica e cidadã dos sujeitos. Respeita-se e valoriza-se, porquanto, o protagonismo social, com vistas à equidade na distribuição de oportunidades justas, visando a condições adequadas para uma sociedade decolonizada. $O$ Programa Pontos de Memória evidencia que se pode experimentar uma ação decolonizadora 
que nasce da estrutura rígida de um Estado, desde que as ações empreendidas por ele sejam coerentes com o propósito que norteia seus princípios e que não existam descontinuidades abruptas e ao mesmo tempo, chances reais de manutenção financeira até que as experiências possam obter formas de autofinanciamento e gestão. Durante o desenvolvimento da pesquisa, notamos que o diálogo e a produção conjunta entre o poder público (representado pelo lbram) e a sociedade civil é possível a partir dos processos museais denominados como Pontos de Memória. Destacamos a necessidade de que o Estado esteja atento aos processos metodológicos de formação, fomento e articulação, nesse caso dever do Estado, sempre em consonância com a perspectiva de manter a autonomia de gestão dos processos museais.

\section{Referências}

BRASIL. Ministério da Cultura. Política Nacional de Museus/organização e textos, José do Nascimento Junior, Mário de Souza Chagas. - Brasília: MinC, 2007. https://www.museus.gov.br/wp-content/uploads/2010/0I/politica_nacional_museus.pdf

BRASIL. Ministério da justiça, Relatório de Gestão, 2007. Programa Nacional de Segurança com Cidadania - PRONASCI.

https://www.justica.gov.br/Acesso/auditorias/arquivos_auditoria/departamento-penitenciario-nacional/2007relatoriogestao_depen_2007.pdf

BRASIL. Ministério da Cultura. Termos de Referência Programa Pontos de Memória.Textos, Fernandes, Daniel. (2010). Produto I.

BRASIL. Ministério da Cultura. Termos de Referência Programa Pontos de Memória. Textos, Gouveia, I. C. (2010/20II). Produto 2.

BRASIL. Ministério da Cultura. Termos de Referência Programa Pontos de Memória. Textos, Gouveia, I. C. (2010/20II). Produto 4.

BRASIL. Ministério da Cultura.Termos de Referência Programa Pontos de Memória. Textos, Gouveia, I. C. (2010/20II). Produto 7.

BRASIL. Ministério da Cultura. Termos de Referência Programa Pontos de Memória. Textos, Holanda, C. R. (20I5). Produto I.

BRASIL. Ministério da Cultura. Termos de Referência Programa Pontos de Memória.Textos, Maltez,Ana (20I3). Produto I.

BRASIL. Ministério da Cultura. Termos de Referência Programa Pontos de Memória. Textos, Schuabb, S. C. (20I3). Produto I.

BRASIL. Ministério da Cultura.Termos de Referência Programa Pontos de Memória.Textos, Fernandes Toledo,W. S. (2009). Produto 2.

BRASIL. Ministério da Cultura. Termos de Referência Programa Pontos de Memória. Textos, Fernandes VARANDA, A, P. M. (20I0). Produto I.

MOUTINHO, Mário Canova. Sobre o conceito de Museologia Social. Cadernos de Sociomuseologia, I993, I.I.

MORAES, Nilson Alves de. Políticas públicas, políticas culturais e museu no Brasil. Revista Museologia e Patrimônio, v. 2, n. I, p. 54-69, 2009.

PEREIRA, Marcele Regina Nogueira. Museologia Decolonial: os Pontos de Memória e a insurgência do fazer museal. Tese de Doutorado. 2018. 
Política Pública de Direito à Memória:

apontamentos sobre a trajetória do Programa Pontos de Memória

PORTILHO, Aline dos Santos. Das 'belezas que emanam dos jardins suspensos de Ipanema e Copacabana': políticas governamentais, demandas por memória e produção do espaço no Museu de Favela do Pavão-Pavãozinho e Cantagalo. 2016. Tese de Doutorado. p. 66

SANTOS, Maria Célia T. Moura. Um compromisso social com a museologia. Revista Cadernos do Ceom, 20 I4, 27.4I: 7I-II4. 